\title{
Chapter 2 \\ Ceramic Coating of Ti and Its Alloys Using Dry Processes for Biomedical Applications
}

\author{
Takatoshi Ueda, Natsumi Kondo, Shota Sado, Ozkan Gokcekaya, \\ Kyosuke Ueda, Kouetsu Ogasawara, and Takayuki Narushima
}

\begin{abstract}
In this chapter, bioceramic coatings on $\mathrm{Ti}$ and its alloys are examined. Surface modification processes of metallic biomaterials are reviewed, and the formation and evaluation of amorphous calcium phosphate (ACP) and anatase-rich $\mathrm{TiO}_{2}$ coatings are described. Dry processes such as radio-frequency (RF) magnetron sputtering and thermal oxidation are employed for coating. Ag-containing ACP coating films exhibited antibacterial activity through the continuous release of $\mathrm{Ag}$ ions, caused by the resorbability of ACP. Anatase-rich $\mathrm{TiO}_{2}$ layers fabricated by a two-step thermal oxidation process showed photodegradation of organic compounds under both UV- and visible-light irradiation. The introduction of $\mathrm{Au}$ into $\mathrm{TiO}_{2}$ layers from Ti-Au alloy substrates by thermal oxidation contributed to the expression of visible-light response.
\end{abstract}

Keywords Calcium phosphate - Silver - Antibacterial activity - Anatase • Photocatalytic activity

\subsection{Introduction}

$\mathrm{Ti}$ and its alloys (along with stainless steels and $\mathrm{Co}-\mathrm{Cr}$ alloys) are recognized as primary metallic biomaterials because of their excellent balance of strength and ductility, along with their high corrosion resistance when forming passivation films, low allergenic nature, and bone compatibility (osseointegration) [1, 2]. However,

\footnotetext{
T. Ueda $\bullet$ N. Kondo $\bullet$ S. Sado $\bullet$ O. Gokcekaya $\bullet$ K. Ueda $\bullet$ T. Narushima $(\square)$ Department of Materials Processing, Tohoku University, 6-6-02 Aza Aoba, Aramaki, Aoba-ku, Sendai, Miyagi 980-8579, Japan e-mail: narut@material.tohoku.ac.jp

K. Ogasawara

Department of Immunobiology, Institute of Development, Aging and Cancer, Tohoku University, 4-1 Seiryo-machi, Aoba-ku, Sendai 980-8579, Japan

Department of Intractable Diseases and Immunology, Tohoku University, 4-1 Seiryo-machi, Aobaku, Sendai 980-8575, Japan 


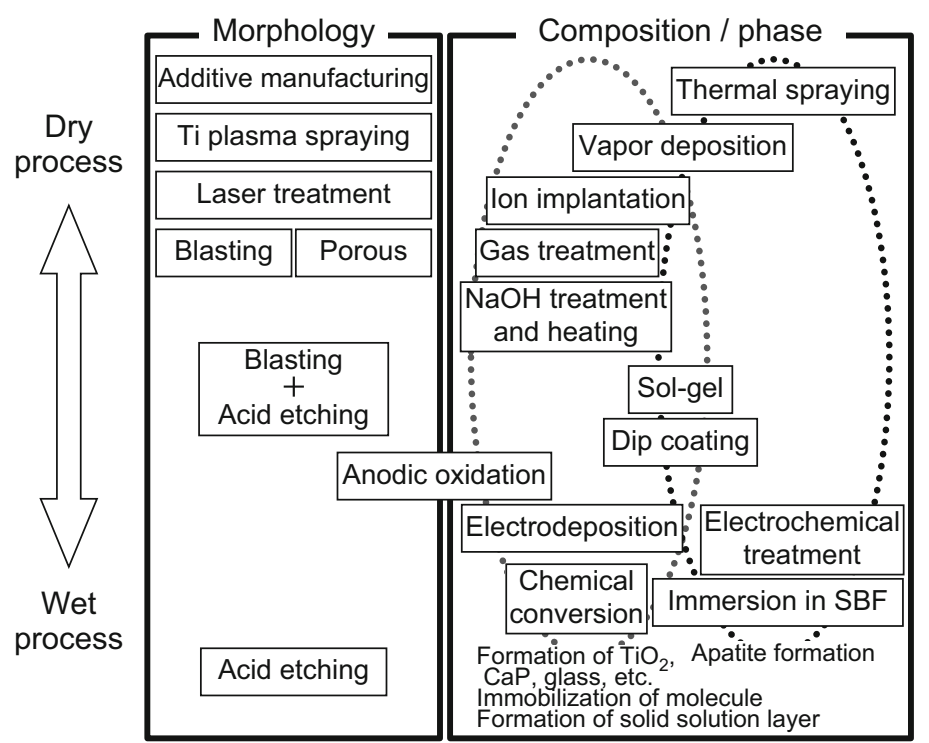

Fig. 2.1 Surface modification processes of metallic biomaterials

biofunctions of metallic biomaterials are insufficient compared to those of ceramic and polymer biomaterials. Some ceramics have chemical compositions close to that of hard tissue and exhibit bioactivity and bioresorbability, while polymers can polymerize to form functional groups and segments for biomedical applications. Therefore, surface modification is necessary to improve the biofunctionality of Ti and its alloys [3,4]. Metallic biomaterial microstructures can generally be controlled to exhibit desired mechanical properties seen in the bulk material, an advantage they hold over ceramic and polymer biomaterials. Surface modification can in turn impart biofunctionality without impacting the bulk properties.

The different processes used for surface modification of metallic biomaterials are summarized in Fig. 2.1 [5]. These techniques are classified into two groups of wet and dry processes. Wet processes use aqueous solution for steps such as immersion and electrifying, while dry processes are based on the reactions of the surface with gases, ions, and plasma. Surface modification can control the morphology, composition, and/or phase of a given material. Controlling the surface morphology allows for high mechanical bonding between metallic biomaterials and hard tissues (mechanical anchoring) and for control of biological reactions of cells and proteins on the modified surface. Acid etching, blasting, laser treatment, additive manufacturing (AM), and porous treatments using beads, Ti plasma spraying, and fiber mesh coating are various examples of these processes.

Controlling the composition/phase of a surface can be conducted through physical, chemical, and biological processes. Since the primary application of metallic biomaterials is for hard-tissue substitution, bioceramics with excellent bone com- 
patibility can be utilized as agents for surface composition/phase control. Processes such as thermal spraying, vapor deposition, electrochemical treatment, and immersion in simulated body fluid (SBF) have been used to coat apatite, which is an analogue for the inorganic components of hard tissues. In addition, $\mathrm{TiO}_{2}$, calcium phosphate, sodium titanate, and $\mathrm{CaTiO}_{3}$ coatings formed by anodic oxidation, gas treatment, $\mathrm{NaOH}$ treatment and heating, ion implantation, and chemical conversion can improve bone compatibility of implant substrates under biological conditions. Anodic oxidation changes both the chemical composition and roughness of a surface. Hybrid coatings of ceramics and polymers are candidates for further improvements in the biofunctionality of metallic biomaterials. To this end, hybrids such as calcium phosphate+collagen and calcium phosphate+bone morphogenetic protein have been seen in recent study [6-8].

In this chapter, the formation and evaluation of ceramic coatings of $\mathrm{Ti}$ and its alloys are described with a focus on their antibacterial potential. Radio-frequency (RF) magnetron sputtering and thermal oxidation are the main processes discussed here for controlling composition/phase of surfaces, which are classified as dry processes. Surgical site infection (SSI) related to implants occurs at rates of $2-30 \%$ depending on the surgical site and the procedure, and SSI is even more frequent after revision surgery $[9,10]$. Several approaches are known to lower the risk of SSI, such as the use of antibiotics. However, prolonged use of antibiotics at higher doses can lead to systematic drug resistance and local toxicity [11]. The use of ceramic coatings with antibacterial activity is a powerful method to mitigate SSI.

\subsection{Antibacterial Properties of Ag-Containing Amorphous Calcium Phosphate Coating Films}

$\mathrm{Ag}, \mathrm{Cu}$, and $\mathrm{Zn}$ ions are known antibacterial agents. Ag ions are effective against many types of bacteria, are less likely to cause bacterial resistance, and express antibacterial activity at lower concentrations than $\mathrm{Cu}$ and $\mathrm{Zn}$ ions [12-14]. Here, amorphous calcium phosphate (ACP) coating films on $\mathrm{Ti}$ and its alloys are fabricated by RF magnetron sputtering and evaluated in vivo and in vitro [15-17]. Coating of implants with Ag-containing ACP is one possible technique for preventing infection; ACP possesses bioresorbability under biological conditions, which causes the continuous release of $\mathrm{Ag}$ ions from such $\mathrm{Ag}$-containing films, creating antibacterial activity for a desired duration. The addition of Ag to HAp (hydroxyapatite, $\left.\mathrm{Ca}_{10}\left(\mathrm{PO}_{4}\right)_{6}(\mathrm{OH})_{2}\right)$ has been studied previously [18-21], but HAp is less resorbable than ACP. Both antibacterial activity and improved bone forming are expected from implants coated with Ag-containing ACP.

Ag-containing $\beta$-TCP ( $\beta$-type tricalcium phosphate, $\mathrm{Ca}_{3} \mathrm{P}_{2} \mathrm{O}_{8}$ ) sintered body was fabricated by hot-pressing $\mathrm{Ag}$ and $\beta$-TCP raw powders as targets in RF magnetron 
Table 2.1 Notation and composition of sputtering targets (mass\%)

\begin{tabular}{l|l|l}
\hline \multirow{2}{*}{ Notation } & \multicolumn{2}{|l}{ Composition } \\
\cline { 2 - 3 } & $\mathrm{Ag}$ & $\beta-\mathrm{TCP}$ \\
\hline 0AgTCP & 0 & 100 \\
\hline 15AgTCP & 15 & 85 \\
\hline 30AgTCP & 30 & 70 \\
\hline
\end{tabular}

sputtering. The Ag content in Ag-containing $\beta$-TCP targets was 0, 15, and 30 mass $\%$ as listed in Table 2.1 . Plates $(10 \times 10 \times 1 \mathrm{~mm})$ of mirror-polished commercially pure (CP) Ti (grade 2) and blasted Ti-6mass\%-Al-4mass\%V (Ti-6Al-4V) alloy were used as substrates. The thickness of the coating films for analysis and evaluation of antibacterial properties was fixed at $0.5 \mu \mathrm{m}$, as controlled by adjusting the deposition time.

Figure 2.2 shows X-ray diffraction (XRD) patterns of the coating films formed on mirror-polished $\mathrm{CP}$ Ti substrates using a 15mass\%-Ag-containing TCP (15AgTCP) target. A broad peak is present at a $2 \theta$ value of $25-35^{\circ}$, which is a characteristic of ACP coating films [15]. Cross-sectional scanning electron microscopy (SEM) images of coating films on mirror-polished CP Ti substrates are present in Fig. 2.3. The coating films are dense and uniform, with good adhesion to the substrates. The deposition rates were $0.02-0.1 \mathrm{~nm} \cdot \mathrm{s}^{-1}$, depending on the target composition and RF power.

The Ag contents of the coating films formed using 15AgTCP and 30AgTCP targets were 2 and 15 mass \%, respectively, lower than those of the targets. Lower $\mathrm{Ag}$ contents compared to target compositions have been previously reported in Ag-containing HAp coating films [22]. These discrepancies may be linked to differences in the ionization rates between elements during sputtering.

E. coli and $S$. aureus, Gram-negative and Gram-positive bacteria, respectively, were used for antibacterial testing. Ag-containing ACP coating films on blasted Ti-6Al-4V substrates were shaking cultured at $200 \mathrm{rpm}$ in 1/500 nutrient broth (NB) solution with an initial bacterial concentration of $1 \times 10^{7} \mathrm{CFU}$ (colony-forming unit) $\cdot \mathrm{mL}^{-1}$ for $E$. coli and $1 \times 10^{5} \mathrm{CFU} \cdot \mathrm{mL}^{-1}$ for $S$. aureus. Solution temperature was maintained at $310 \mathrm{~K}$ and incubation was carried out for 10.8 and $86.4 \mathrm{ks}$. Afterward, the numbers of viable bacteria colonies were counted using a smear-plate culture method.

Figure 2.4 shows the relationship between the incubation time and the number of viable bacteria for coating films formed on blasted Ti-6Al-4V substrates using a $15 \mathrm{AgTCP}$ target. After incubation for $10.8 \mathrm{ks}$, the number of viable $E$. coli was less than 1 , which was plotted as $10^{\circ} \mathrm{CFU}$. The number of viable $S$. aureus decreased after incubation for $10.8 \mathrm{ks}$ and became less than 1 after incubation for $86.4 \mathrm{ks}$.

The amounts of $\mathrm{Ca}$, P-related, and $\mathrm{Ag}$ ions after immersion of Ag-containing ACP coating films in the $1 / 500 \mathrm{NB}$ solution with shaking at $200 \mathrm{rpm}$ are depicted in Fig. 2.5. Ag ions elute from the Ag-containing ACP coating films and exhibit antibacterial activity. The $\mathrm{Ag}$ ion concentration was almost constant over all measured immersion times, caused by the formation of $\mathrm{AgCl}$ between the eluted $\mathrm{Ag}^{+}$and $\mathrm{Cl}^{-}$ present in the $1 / 500 \mathrm{NB}$ solution. 
Fig. 2.2 XRD patterns of coating films fabricated on mirror-polished CP Ti substrates at RF powers of 50,100 , and $150 \mathrm{~W}$ using a 15AgTCP target
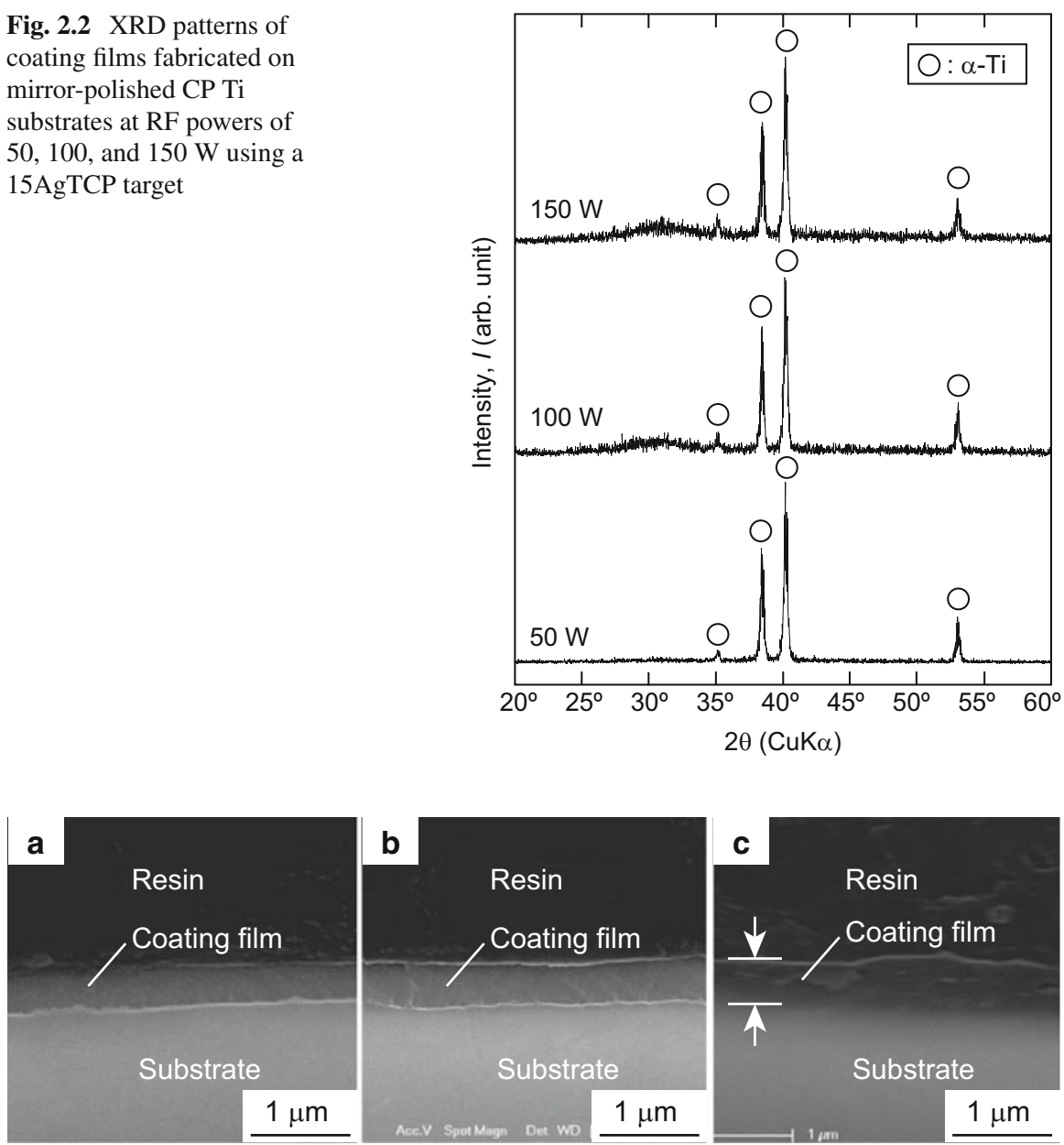

Fig. 2.3 Cross-sectional SEM image of coating films fabricated on mirror-polished CP Ti substrates using (a) $0 \mathrm{AgTCP}$, (b) 15AgTCP, and (c) 30AgTCP targets

\subsection{Photocatalytic Activity of $\mathrm{TiO}_{2}$ Layers Formed by Two-Step Thermal Oxidation}

\subsubsection{UV (Ultraviolet) Response}

$\mathrm{TiO}_{2}$ layers have been used as surface coatings of Ti implants [23], as $\mathrm{TiO}_{2}$ exhibits photocatalytic activity under UV-light irradiation, such as photoinduced superhydrophilicity and photodegradation of organic compounds [24]. The photoinduced superhydrophilicity of $\mathrm{TiO}_{2}$ layers on $\mathrm{Ti}$ improves bone compatibility [25, 26], and photodegradation contributes to the antibacterial activity of Ti implants by killing 

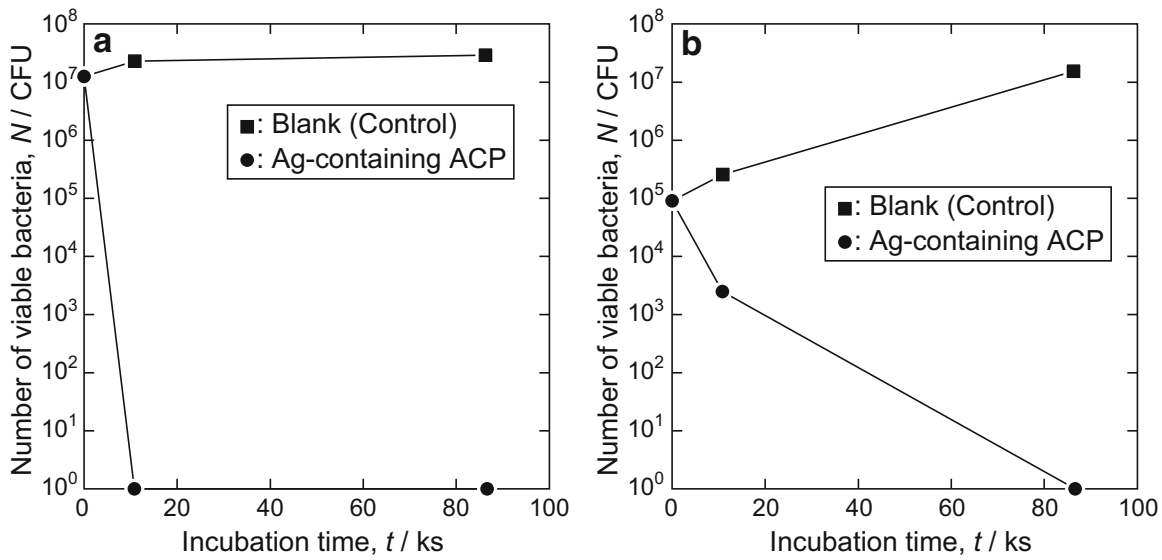

Fig. 2.4 Number of viable (a) E. coli and (b) S. aureus after incubation with Ag-containing ACP coating films fabricated on blasted Ti-6Al-4V substrates using a $15 \mathrm{AgTCP}$ target

Fig. 2.5 Amounts of $\mathrm{Ca}$, P-related, and $\mathrm{Ag}$ ions in $1 / 500 \mathrm{NB}$ solution after immersion of Ag-containing ACP coating films fabricated on blasted Ti-6Al-4V using a $15 \mathrm{AgTCP}$ target

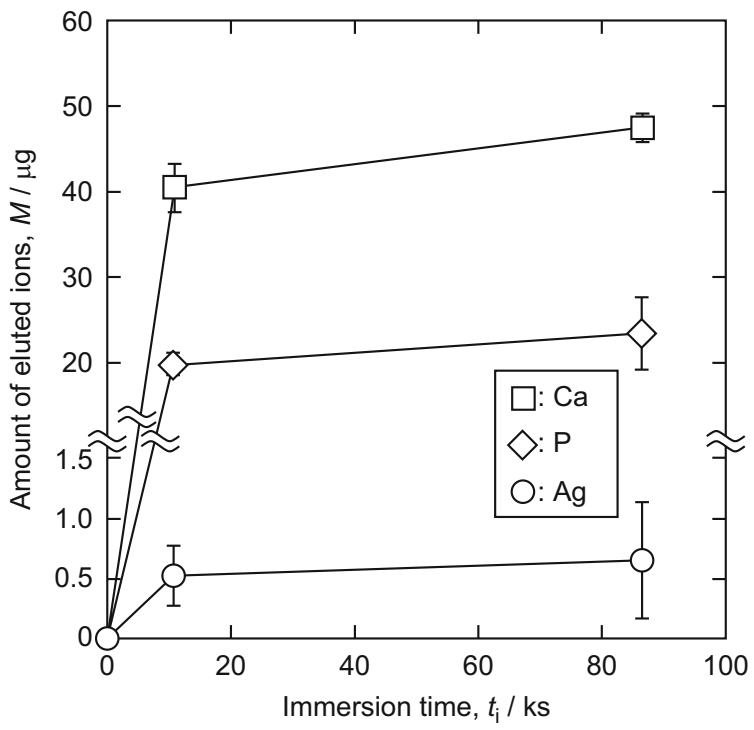

nearby bacteria through radical formation $[27,28]$. Rutile is a thermodynamically stable phase of $\mathrm{TiO}_{2}$ with a band gap of $3.0 \mathrm{eV}$, while anatase is a metastable phase of $\mathrm{TiO}_{2}$ having a band gap of $3.2 \mathrm{eV}$. The lifetimes of these electronic excitations are an order of magnitude larger for anatase as compared to rutile [29], and as such the higher photocatalytic activity is expected in anatase.

The present authors presented a two-step thermal oxidation process for the fabrication of anatase-rich $\mathrm{TiO}_{2}$ layer on $\mathrm{Ti}$ and its alloys [30-32], consisting of initial 
Fig. 2.6 Effects of the anatase fraction in the $\mathrm{TiO}_{2}$ layers on the rate constant of methylene blue degradation under UV-light irradiation for $\mathrm{CP}$ Ti and the Ti-25mass\%Mo and Ti-25mass\% $\mathrm{Nb}$ alloys [Reprinted from Ref. [32] with permission from Elsevier]

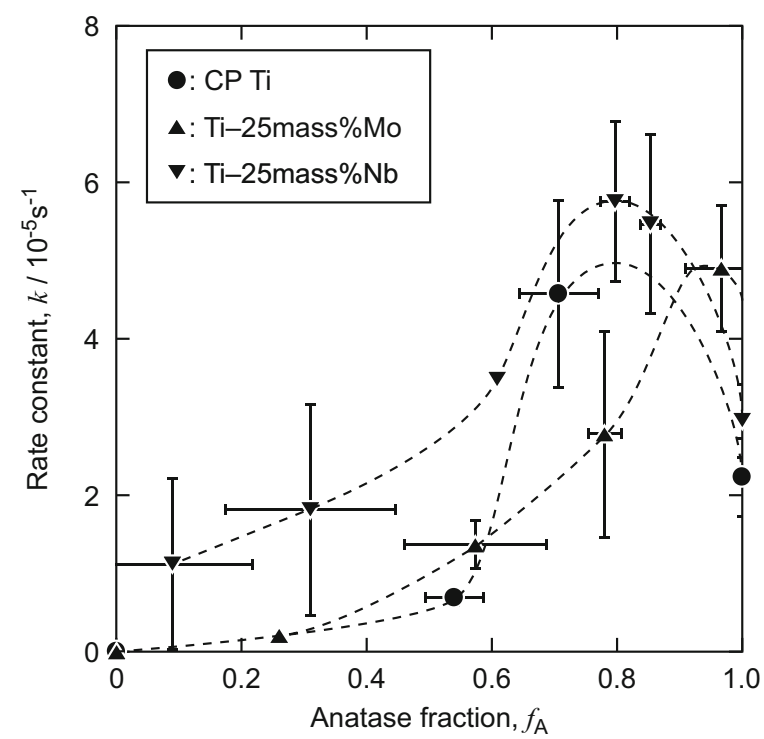

treatment under $\mathrm{CO}$-containing atmosphere and subsequent treatment in air, and evaluated the photocatalytic activity of anatase-containing $\mathrm{TiO}_{2}$ layers on $\mathrm{CP} \mathrm{Ti}$ and Ti-25mass $\%$ Mo and Ti-25mass $\% \mathrm{Nb}$ alloys [32]. The anatase fraction in the $\mathrm{TiO}_{2}$ layer can be controlled during this process by controlling the temperature of the second step. By using $\mathrm{TiO}_{2}$ layers with various anatase fractions, the degradation rate of methylene blue (MB) under UV-light irradiation was measured. Illumination was performed using a UV lamp with a central wavelength of $351 \mathrm{~nm}$. The UV-light intensity was $1.0 \mathrm{~mW} \cdot \mathrm{cm}^{-2}$ at the surface of the specimen. The effects of anatase fraction on the MB degradation rates are summarized in Fig. 2.6 [32], where the maximum rate was obtained at an anatase fraction of approximately 0.8 for both $\mathrm{CP}$ $\mathrm{Ti}$ and its alloys. Su et al. [33] measured the $\mathrm{MB}$ degradation rates of $\mathrm{TiO}_{2}$ films on CP Ti formed by anodic oxidation, where the grain sizes, surface areas, and crystallinity of the $\mathrm{TiO}_{2}$ films were fixed, but the anatase fraction was varied. They reported a maximum decomposition rate at an anatase fraction of approximately 0.6 and indicated that electrons that are photoexcited in rutile can migrate to the conduction band of anatase to leave electron holes in the rutile; as a result, recombination is effectively suppressed in anatase-rich $\mathrm{TiO}_{2}$ layers. In our case, the second step temperature was altered to control the resulting anatase fraction, but the thickness and surface roughness were not controlled. Nevertheless, a similar dependence of decomposition rate upon the anatase fraction was obtained compared to $\mathrm{Su}$ et al.; these anatase-rich $\mathrm{TiO}_{2}$ layers show excellent photodegradation of organic compounds. 


\subsubsection{Visible-Light Response}

The visible-light-responsive photocatalytic activity of implants is useful for antibacterial activity during operation and in the reactivation of implants. Because SSI is caused by endogenous flora in the patient's skin, mucous membranes, or hollow viscera, SSI cannot simply be prevented by sterilization before operation [34]. In order to express the photocatalytic activity of $\mathrm{TiO}_{2}, \mathrm{UV}$-light irradiation is generally required, which is harmful to the human body. Therefore, visible-light response is more desirable for preventing infection during operation. Reactivation of implants is required during usage for some periods in a human body. While UV-light irradiation is known to reactivate Ti implant surfaces [35], reactivation using visible-light irradiation is more favorable for the human body.

Au solutes in $\mathrm{TiO}_{2}$ [36] and the addition of metallic Au nanoparticles to $\mathrm{TiO}_{2}$ [36, 37] can lead to visible-light response. Therefore, two-step thermal oxidation was applied to a Ti-Au alloy in order to fabricate Au-containing $\mathrm{TiO}_{2}$ layers with visiblelight-responsive photocatalytic activity. Ti-4.2at\% Au alloy was employed as a substrate material. The first step treatment was conducted under an Ar-1\%CO atmosphere at $1073 \mathrm{~K}$ for $3.6 \mathrm{ks}$, and the subsequent second step treatment was conducted in air at $673 \mathrm{~K}$ for $10.8 \mathrm{ks}$. An anatase-rich $\mathrm{TiO}_{2}$ layer was obtained on the Ti-4.2at\% Au alloy substrate after this process. Figure 2.7 depicts the crosssectional microstructure of the anatase-rich $\mathrm{TiO}_{2}$ layer as observed via transmission electron microscopy (TEM). Au nanoparticles can be seen here as small black particles approximately $5 \mathrm{~nm}$ in diameter.

The photocatalytic activity of the Au-containing $\mathrm{TiO}_{2}$ layer was evaluated by self-cleaning tests (JIS R 1753: 2013) based on the decomposition of a layer of steric acid on the $\mathrm{Au}$-containing $\mathrm{TiO}_{2}$ layer under visible-light irradiation, where the steric acid layer was prepared by dip coating. Substrates with this steric acid layer were irradiated with visible light with an intensity of $10 \mathrm{~mW} \cdot \mathrm{cm}^{-2}$ at the surface of the steric acid layer, for as long as $86.4 \mathrm{ks}$. The light source was a Xe lamp with a UV filter to produce light of $\lambda>400 \mathrm{~nm}$. Changes in the water contact angles under visible-light irradiation were measured to determine the extent of steric acid photodegradation, and the $\mathrm{TiO}_{2}$ layer expressed visible-light-responsive photocatalytic activity.

Figure 2.8 shows the changes in water contact angles on as-polished and two-step (i.e., after two-step thermal oxidation) $\mathrm{CP}$ Ti and Ti-4.2at\% Au substrates under visible-light irradiation [38]. The water contact angles on the as-polished specimens remained almost constant, indicating no visible-light response. On the other hand, the two-step specimens showed decreased water contact angles. For the two-step Ti-4.2at\%Au alloy, the water contact angle decreased from 80 to $10^{\circ}$. Silva et al. [37] reported that electrons in Au nanoparticles (1.87-6.40 $\mathrm{nm}$ in diameter) attached on $\mathrm{TiO}_{2}$ particles were excited by surface plasmon resonance and migrated to $\mathrm{TiO}_{2}$ particles, producing $\mathrm{H}_{2}$ by the photoreduction of $\mathrm{H}_{2} \mathrm{O}$. The $\mathrm{Au}$ particle size recommended in their study is close to that of our study (Fig. 2.7). One possible mechanism of visible-light response in the $\mathrm{Au}$-containing $\mathrm{TiO}_{2}$ layer formed by two-step thermal oxidation involves the decrease in band gap due to $\mathrm{Au}$ solutes in the $\mathrm{TiO}_{2}$ layer [36] and/or the surface plasmon resonance of the Au nanoparticles in the $\mathrm{TiO}_{2}$ layer [37]. 
Fig. 2.7 Cross-sectional TEM image of

Ti-4.2at\% Au alloy after two-step thermal oxidation

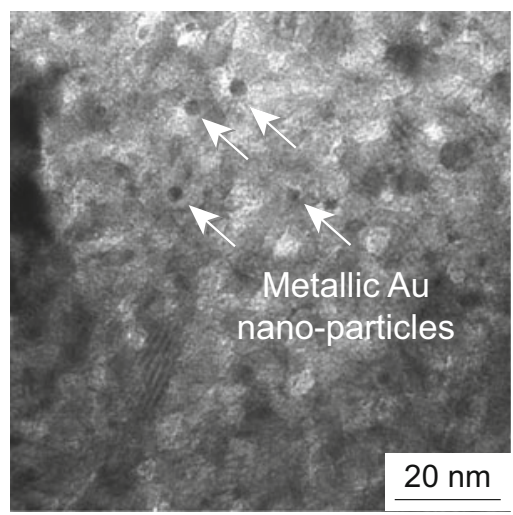

Fig. 2.8 Measured water contact angles on the as-polished and two-step $\mathrm{CP} \mathrm{Ti}$ and $\mathrm{Ti}-4.2 \mathrm{at} \% \mathrm{Au}$ alloy substrates during visible-light irradiation

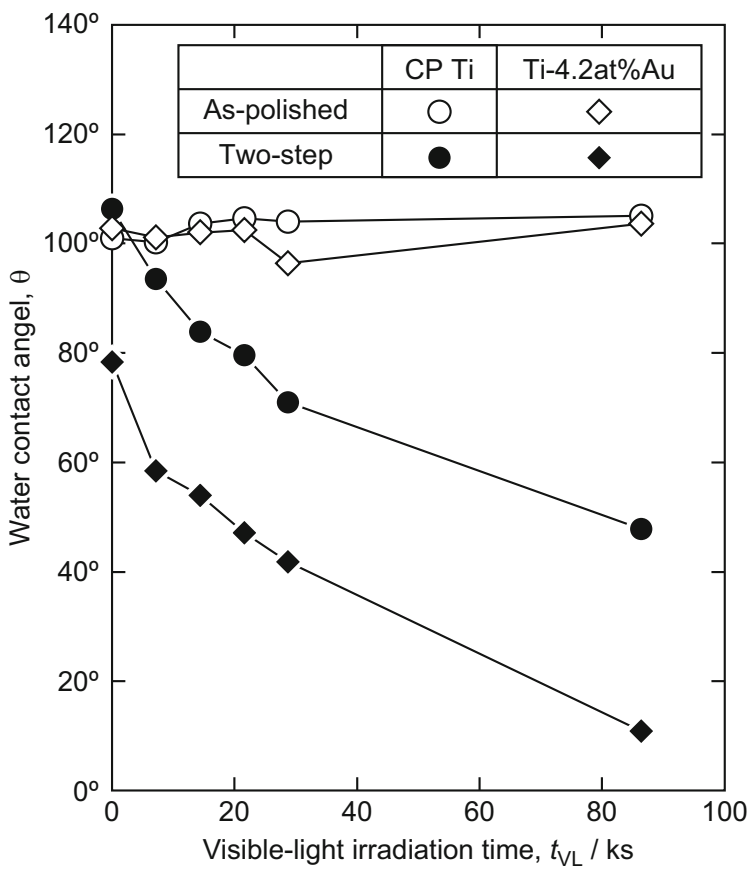

\subsection{Summary}

The surface modification of Ti and its alloys using ceramic coatings and their antibacterial activity were described in this chapter. Both Ag-containing ACP coating films and Au-containing $\mathrm{TiO}_{2}$ layers, fabricated by $\mathrm{RF}$ magnetron sputtering and two-step thermal oxidation, respectively, indicated antibacterial activity. Control over Ag ion elution from Ag-containing ACP coating films and the improved visible-light response of $\mathrm{Au}$-containing $\mathrm{TiO}_{2}$ layers will be discussed in future publications. 


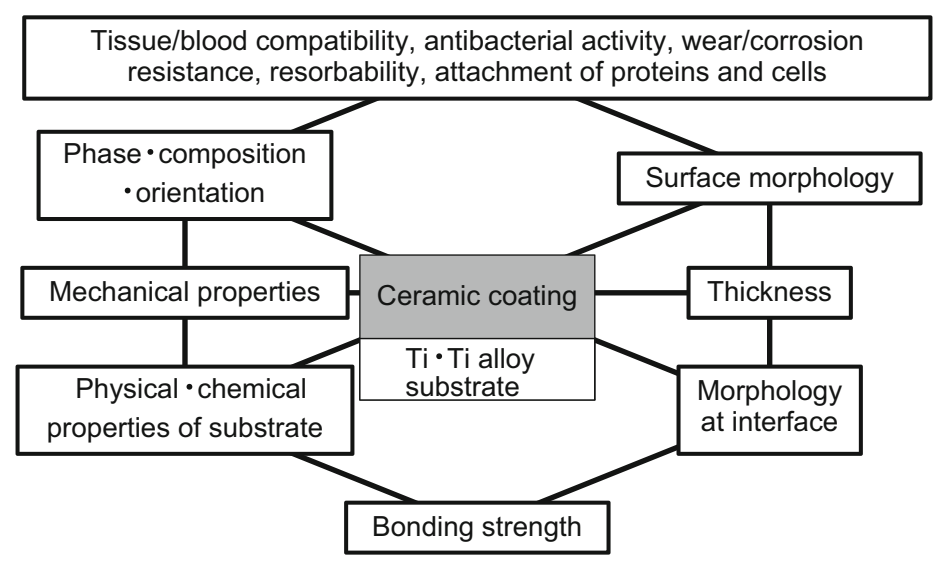

Fig. 2.9 Factors in biomedical ceramic coatings on $\mathrm{Ti}$ and its alloy substrates

Ti and its alloys are expected to see continued use as metallic biomaterials for implants. Figure 2.9 shows factors that must be considered when developing ceramic coatings on Ti and its alloy substrates for biomedical applications [5]. The interface between a coating film and the human body requires designed properties such as hard/soft tissue and blood compatibilities, antibacterial activity, wear and corrosion resistance, resorbability, and suppression/enhancement of protein and cell attachment. These properties are affected by surface morphology, phase, composition, and orientation of the coating films. High-strength and durable bonding between a coating film and substrates, which are affected by physical and chemical properties of the substrates and the morphology at the interface, are also crucial. Therefore, the mechanical properties and thickness of coating films, as well as the reaction between coating film and substrates, must be taken into consideration.

Acknowledgments This study was supported in part by a Grant-in-Aid for Scientific Research from the Ministry of Education, Culture, Sports, Science and Technology (MEXT), Japan (Nos. 25249094 and 26709049).

\section{References}

1. Narushima T. Titanium and its alloys as biomaterials. J Jpn Light Metals. 2005;55:561-5.

2. Niinomi M, Hanawa T, Narushima T. Japanese research and development on metallic biomedical, dental, and healthcare materials. JOM. 2005;57(4):18-24.

3. Narushima T. Surface modification for improving biocompatibility of titanium materials with bone. J Jpn Light Metals. 2008;58:577-82.

4. Hanawa T. Biofunctionalization of titanium for dental implant. Jpn Dent Sci Rev. 2010;46:93-101.

5. Goto T, Narushima T, Ueda K. Bio-ceramic coating on titanium by physical and chemical vapor deposition. In: Zhang S, editor. CRC handbook of biological and biomedical coatings. Boca Raton: CRC Press; 2011. p. 299-332. 
6. de Jonge LT, Leeuwenburgh SCG, van den Beucken JJJP, te Riet J, Daamen WF, Wolke JGC, Scharnweber D, Jansen JA. The osteogenic effect of electrosprayed nanoscale collagen/calcium phosphate coatings on titanium. Biomaterials. 2010;31:2461-9.

7. Xie CM, Lu X, Wang KF, Meng FZ, Jiang O, Zhang HP, Zhi W, Fang LM. Silver nanoparticles and growth factors incorporated hydroxyapatite coatings on metallic implant surfaces for enhancement of osteoinductivity and antibacterial properties. ACS Appl Mater Interfaces. 2014;6:8580-9.

8. Ramazanoglu M, Lutz R, Ergun C, von Wilmowsky C, Nkenke E, Schlegel KA. The effect of combined delivery of recombinant human bone morphogenetic protein-2 and recombinant human vascular endothelial growth factor 165 from biomimetic calcium-phosphate-coated implants on osseointegration. Clin Oral Implants Res. 2011;22:1433-9.

9. Hickok NJ, Shapiro IM. Immobilized antibiotics to prevent orthopaedic implant infections. Adv Drug Deliv Rev. 2012;64:1165-76.

10. Haenle M, Fritsche A, Zietz C, Bader R, Heidenau F, Mittelmeier W, Gollwitzer H. An extended spectrum bactericidal titanium dioxide $\left(\mathrm{TiO}_{2}\right)$ coating for metallic implants: in vitro effectiveness against MRSA and mechanical properties. J Mater Sci Mater Med. 2011;22:381-7.

11. Goodman SB, Yao Z, Keeney M, Yang F. The future of biologic coatings for orthopaedic implants. Biomaterials. 2013;34:3174-83.

12. Ferraris S, Spriano S. Antibacterial titanium surfaces for medical implants. Mater Sci Eng C. 2016;61:965-78.

13. Du W-L, Niu S-S, Xu Y-L, Xu Z-R, Fan C-L. Antibacterial activity of chitosan tripolyphosphate nanoparticles loaded with various metal ions. Carbohydr Polym. 2009;75:385-9.

14. Monteiro DR, Gorup LF, Takamiya AS, Ruvollo-Filho AC, de Camargo ER, Barbosa DB. The growing importance of materials that prevent microbial adhesion: antimicrobial effect of medical devices containing silver. Int J Antimicrob Agents. 2009;34:103-10.

15. Narushima T, Ueda K, Goto T, Masumoto H, Katsube T, Kawamura H, Ouchi C, Iguchi Y. Preparation of calcium phosphate films by radiofrequency magnetron sputtering. Mater Trans. 2005;46:2246-52.

16. Ueda K, Narushima T, Goto T, Taira M, Katsube T. Fabrication of calcium phosphate films for coating on titanium substrates heated up to $773 \mathrm{~K}$ by RF magnetron sputtering and their evaluations. Biomed Mater. 2007;2:S160-6.

17. Yokota S, Nishiwaki N, Ueda K, Narushima T, Kawamura H, Takahashi T. Evaluation of thin amorphous calcium phosphate coatings on titanium dental implants deposited using magnetron sputtering. Implant Dent. 2014;23:343-50.

18. Chen W, Liu Y, Courtney HS, Bettenga M, Agrawal CM, Bumgardner JD, Ong JL. In vitro anti-bacterial and biological properties of magnetron co-sputtered silver-containing hydroxyapatite coating. Biomaterials. 2006;27:5512-7.

19. Bai X, More K, Rouleau CM, Rabiei A. Functionally graded hydroxyapatite coatings doped with antibacterial components. Acta Biomater. 2010;6:2264-73.

20. Trujillo NA, Oldinski RA, Ma H, Bryers JD, Williams JD, Popat KC. Antibacterial effects of silver-doped hydroxyapatite thin films sputter deposited on titanium. Mater Sci Eng C. 2012;32:2135-44.

21. Jelinek M, Kocourek T, Remsa J, Weiserová M, Jurek K, Mikšovský J, Strnad J, Galandáková A, Ulrichová J. Antibacterial, cytotoxicity and physical properties of laser - silver doped hydroxyapatite layers. Mater Sci Eng C. 2013;33:1242-6.

22. Ivanova AA, Surmeneva MA, Tyurin AI, Pirozhkova TS, Shuvarin IA, Prymak O, Epple M, Chaikina MV, Surmenev RA. Fabrication and physico-mechanical properties of thin magnetron sputter deposited silver-containing hydroxyapatite films. Appl Surf Sci. 2016;360:929-35.

23. Degidi M, Nardi D, Piattelli A. 10-year follow-up of immediately loaded implants with TiUnite porous anodized surface. Clin Implant Dent Relat Res. 2012;14:828-38.

24. Fujishima A, Zhang X, Tryk DA. $\mathrm{TiO}_{2}$ photocatalysis and related surface phenomena. Surf Sci Rep. 2008;63:515-82. 
25. Aita H, Hori N, Takeuchi M, Suzuki T, Yamada M, Anpo M, Ogawa T. The effect of ultraviolet functionalization of titanium on integration with bone. Biomaterials. 2009;30:1015-25.

26. Sawase T, Jimbo R, Baba K, Shibata Y, Ikeda T, Atsuta M. Photo-induced hydrophilicity enhances initial cell behavior and early bone apposition. Clin Oral Implants Res. 2008; 19:491-6.

27. Sunada K, Watanabe T, Hashimoto K. Studies on photokilling of bacteria on $\mathrm{TiO}_{2}$ thin film. J Photochem Photobiol A Chem. 2003;156:227-33.

28. Sousa VM, Manaia CM, Mendes A, Nunes OC. Photoinactivation of various antibiotic resistant strains of Escherichia coli using a paint coat. J Photochem Photobiol A Chem. 2013;251:148-53.

29. Xu M, Gao Y, Moreno EM, Kunst M, Muhler M, Wang Y, Idriss H, Wöll C. Photocatalytic activity of bulk $\mathrm{TiO}_{2}$ anatase and rutile single crystals using infrared absorption spectroscopy. Phys Rev Lett. 2011;106:138302.

30. Okazumi T, Ueda K, Tajima K, Umetsu N, Narushima T. Anatase formation on titanium by two-step thermal oxidation. J Mater Sci. 2011;46:2998-3005.

31. Umetsu N, Sado S, Ueda K, Tajima K, Narushima T. Formation of anatase on commercially pure Ti by two-step thermal oxidation using $\mathrm{N}_{2}$-CO gas. Mater Trans. 2013;54:1302-7.

32. Sado S, Ueda T, Ueda K, Narushima T. Formation of $\mathrm{TiO}_{2}$ layers on $\mathrm{CP} \mathrm{Ti}$ and $\mathrm{Ti}-\mathrm{Mo}$ and $\mathrm{Ti}-\mathrm{Nb}$ alloys by two-step thermal oxidation and their photocatalytic activity. Appl Surf Sci. 2015;357:2198-205.

33. Su R, Bechstein R, Sø L, Vang RT, Sillassen M, Esbjörnsson B, Palmqvist A, Besenbacher F. How the anatase-to-rutile ratio influences the photoreactivity of $\mathrm{TiO}_{2}$. J Phys Chem C. 2011;115:24287-92.

34. Mangram AJ, Horan TC, Pearson ML, Silver LC, Jarvis WR. Guideline for prevention of surgical site infection, 1999. Infect Control Hosp Epidemiol. 1999;20:247-78.

35. Att W, Hori N, Iwasa F, Yamada M, Ueno T, Ogawa T. The effect of UV-photofunctionalization on the time-related bioactivity of titanium and chromium-cobalt alloys. Biomaterials. 2009;30:4268-76.

36. Li XZ, Li FB. Study of $\mathrm{Au} / \mathrm{Au}^{3+}-\mathrm{TiO}_{2}$ photocatalysts toward visible photooxidation for water and wastewater treatment. Environ Sci Technol. 2001;35:2381-7.

37. Silva CG, Juárez R, Marino T, Molinari R, García H. Influence of excitation wavelength (UV or visible light) on the photocatalytic activity of titania containing gold nanoparticles for the generation of hydrogen or oxygen from water. J Am Chem Soc. 2011;133:595-602.

38. Ueda T, Sado S, Ueda K, Narushima T. Formation of $\mathrm{TiO}_{2}$ layers on Ti-Au alloy using two-step thermal oxidation and their visible-light photocatalytic activity. Mater Lett. in press.

Open Access This chapter is distributed under the terms of the Creative Commons Attribution 4.0 International License (http://creativecommons.org/licenses/by/4.0/), which permits use, duplication, adaptation, distribution and reproduction in any medium or format, as long as you give appropriate credit to the original author(s) and the source, provide a link to the Creative Commons license and indicate if changes were made.

The images or other third party material in this chapter are included in the work's Creative Commons license, unless indicated otherwise in the credit line; if such material is not included in the work's Creative Commons license and the respective action is not permitted by statutory regulation, users will need to obtain permission from the license holder to duplicate, adapt or reproduce the material.

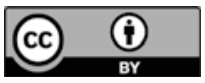

